\title{
BMJ Open Effects of removing reimbursement restrictions on targeted therapy accessibility for non-small cell lung cancer treatment in Taiwan: an interrupted time series study
}

\author{
Jason C Hsu, ${ }^{01}$ Chen-Fang Wei, ${ }^{2}$ Szu-Chun Yang ${ }^{3}$
}

To cite: Hsu JC, Wei C-F, Yang S-C. Effects of removing reimbursement restrictions on targeted therapy accessibility for non-small cell lung cancer treatment in Taiwan: an interrupted time series study. BMJ Open 2019;9:e022293. doi:10.1136/ bmjopen-2018-022293

- Prepublication history for this paper is available online. To view these files, please visit the journal online (http://dx.doi org/10.1136/bmjopen-2018022293).

Received 21 February 2018 Revised 3 December 2018 Accepted 31 January 2019

Check for updates

(C) Author(s) (or their employer(s)) 2019. Re-use permitted under CC BY-NC. No commercial re-use. See rights and permissions. Published by BMJ.

${ }^{1}$ School of Pharmacy and Institute of Clinical Pharmacy and Pharmaceutical Sciences, College of Medicine, National Cheng Kung University, Tainan City, Taiwan

${ }^{2}$ Department of Pharmacy, National Taiwan University Hospital Hsin-Chu Branch, Hsinchu, Taiwan

${ }^{3}$ Department of Internal Medicine, National Cheng Kung University Hospital, Tainan, Taiwan

Correspondence to

Dr Jason C Hsu;

jasonhsuharvard@gmail.com

\section{ABSTRACT}

Interventions Targeted therapies have been proven to provide clinical benefits to patients with metastatic non-small cell lung cancer (NSCLC). Gefitinib was initially approved and reimbursed as a third-line therapy for patients with advanced NSCLC by the Taiwan National Health Insurance (NHI) in 2004; subsequently it became a second-line therapy (in 2007) and further a first-line therapy (in 2011) for patients with epidermal growth factor receptor mutation-positive advanced NSCLC. Another targeted therapy, erlotinib, was initially approved as a third-line therapy in 2007, and it became a second-line therapy in 2008.

Objectives This study is aimed towards an exploration of the impacts of the Taiwan NHI reimbursement policies (removing reimbursement restrictions) related to accessibility of targeted therapies.

Setting We retrieved 2004-2013 claims data for all patients with lung cancer diagnoses from the NHI Research Database. Design and outcome measures Using an interrupted time series design and segmented regression, we estimated changes in the monthly prescribing rate by patient number and market shares by cost following each modification of the reimbursement policy for gefitinib and erlotinib for NSCLC treatment.

Results Totally 92220 patients with NSCLC were identified. The prescribing rate of the targeted therapies increased by $15.58 \%$, decreased by $10.98 \%$ and increased by $6.31 \%$ following the introduction of gefitinib as a second-line treatment in 2007, erlotinib as a second-line treatment in 2008 and gefitinib as as first line treatment in 2011, respectively. The average time to prescription reduced by $65.84 \%$ and $41.59 \%$ following coverage of erlotinib by insurance and gefitinib/erlotinib as second-line treatments in 2007-2008 and following gefitinib as the first-line treatment in 2011.

Conclusions The changes in reimbursement policies had a significant impact on the accessibility of targeted therapies for NSCLC treatment. Removing reimbursement restrictions can significantly increase the level and the speed of drug accessibility.

\section{INTRODUCTION}

Lung cancer is the leading cause of cancer deaths worldwide. ${ }^{1}$ In USA, in 2011,
Strengths and limitations of this study

Both prescription rate and speed (time to prescription) were used to measure drug accessibility.

- An interrupted time-series design, a strong quasi-experimental method, was applied.

- A segmented linear regression model was used to estimate postpolicy changes in both the level and trend of these study outcomes.

- Data from the claims' database of the Taiwan National Health Insurance research Database were analysed that did not cover data for payments made by the patients themselves.

approximately 221130 new cases of lung cancer ( $14 \%$ of all cancer diagnoses) were predicted, out of which 156940 deaths (27\% of cancer deaths) were estimated to have been due to lung cancer. ${ }^{2}$ In Taiwan, lung cancer is also one of the most commonly diagnosed cancers as well as the leading cause of cancer deaths. Approximately 11692 new cases of lung cancer ( $12 \%$ of all cancer diagnoses) and 8587 deaths (20\% of cancer deaths) were predicted to occur in Taiwan in 2012. ${ }^{3}$ About $85 \%$ of all lung cancers are identified as non-small cell, and approximately $75 \%$ of these are metastatic or advanced at diagnosis, for which no curative treatment is available. ${ }^{4-7}$

Since 2004, oral targeted therapies for non-small cell lung cancer (NSCLC) have been launched in the market for patients with epidermal growth factor receptor (EGFR) mutation in Taiwan. Two targeted drugs, gefitinib and erlotinib, were first approved as third-line therapy for patients with advanced NSCLC by the Taiwan Food and Drug Administration, based on results of randomised clinical trials. $^{8-10}$ For patients with advanced NSCLC with mutation-positive EGFR, two drugs were further suggested to be used as 
first-line therapy by the recent National Comprehensive Cancer Network guideline, ${ }^{11}$ as a result of the cumulative evidence showing a significant association between mutated EGFR and because of their clinical benefits. ${ }^{812-14}$

According to 'Directions for Drug Restricted Benefits for National Health Insurance', gefitinib and erlotinib have been reimbursed for the treatment of lung cancer in Taiwan since 2004 and 2007, respectively. When reimbursement for gefitinib by the health insurance began in November 2004, considering the potential significant impact of its use on the healthcare drug expenditure budget, its use was limited only to patients with NSCLC who had previously used platinum and docetaxel or paclitaxel chemotherapy, but who still partially progressed or metastasised (for the third-line treatment). Later, clinical studies have confirmed that the efficacy and safety of gefitinib are better than those for chemotherapy drugs, and that clinical treatment guidelines are recommended for second-line treatment. To improve the accessibility of drugs and early use of new drugs, in November 2007, the Taiwan National Health Insurance (NHI) began to pay for gefitinib as a second-line treatment for patients who had previously used first-line platinum-containing chemotherapy, or patients 70 years of age or older who had received first-line chemotherapy but were still partially exacerbated or metastatic. ${ }^{14}{ }^{15}$ Finally, because clinical studies have confirmed that the efficacy of first-line therapy is better than that of posterior therapy, gefitinib has been further allowed to be used as a first-line therapy for patients with EGFR mutation-positive advanced NSCLC since June 2011. ${ }^{12} 1617$ Similarly, erlotinib's use was limited for a third-line treatment in the begining (June 2007), and it has been further allowed to be used as a first-line therapy for patients with EGFR mutation-positive advanced NSCLC since June 2013. ${ }^{18-22}$

Little is known about the impacts of changes in targeted therapy-related reimbursement policies (related to removing reimbursement restrictions and broadening the eligible patient population) in Taiwan. The aim of our longitudinal analyses was to address this gap by examining the recent trends in utilisation of and expenditures for targeted therapies (gefitinib and erlotinib) following changes in the reimbursement policy, which involve the accessibility and economic burden of drugs. Furthermore, we also evaluated the changes in time to prescription of NSCLC over time.

\section{METHOD}

\section{Data sources}

All monthly claims data, including prescription details and insurer spending, for antineoplastic agents between 2004 and 2013 were retrieved from Taiwan's National Health Insurance Research Database (NHIRD). The database contains information from a nationwide, mandatory-enrolment, single-payer healthcare system created in 1995. Nearly $99 \%$ of the Taiwanese population (around 23 million residents) is enrolled, and this system contracts with $97 \%$ of hospitals and clinics throughout the country. The NHI covers a wide range of prescription medicines as well as inpatient and outpatient medical services. ${ }^{23}$ NSCLC-related prescriptions were identified using the International Classification of Diseases, Ninth Revision diagnosis codes for cancer (codes: 162). Patients with small cell lung cancer and patients who had used etoposide and topotecan were not included in the study.

\section{Drugs of interest}

We used the Anatomical Therapeutic Chemical (ATC) Classification System from WHO. We identified all antineoplastic agents using the ATC code 'L01'. Targeted therapies included in the analysis were protein kinase inhibitors (gefitinib and erlotinib). New targeted therapies (afatinib, crizotinib and ceritinib) were not included in this study because they were not reimbursable by NHI prior to 2013.

\section{Measurements}

To examine the trends in the accessibility of targeted therapies (gefitinib and erlotinib) following the changes in reimbursement policies, we calculated the monthly number of patients who used each targeted therapy and the related costs from 2004 to 2013. Then, we estimated the proportion of their use by patient number and the market share by cost among total patient numbers and total costs of all antineoplastic agents. The prescribing rate of the targeted therapies by patient number was estimated by using the number of patients who had used the targeted therapies divided by the number of patients who had used antineoplastic agents, and the market share of targeted therapies by cost was estimated by using the cost of the targeted therapies divided by the cost of antineoplastic agents. The cost was adjusted using the yearly Consumer Price Index (CPI). ${ }^{24}$

\section{Statistical analysis}

The interrupted time series design, ${ }^{25}$ a strong quasi-experimental method, was adopted to evaluate the overall changes in drug utilisation (prescribing rate and market share of cost) before and after the four modifications to the drug reimbursement policy: (1) Erlotinib was covered by NHI in June 2007. (2) Gefitinib became available as a second-line treatment in November 2007. (3) Erlotinib became available as a second-line treatment in June 2008. (4) Gefitinib became available as a first-line treatment in June 2011. For average time to prescription, we combined the previous three policy changes as one intervention due to the fact that their timing was similar.

A segmented linear regression model was used to estimate postpolicy changes in both the level and trend of these study outcomes. ${ }^{26-29}$ Using baseline trends, we projected rates over time with the assumption that the baseline trend reflected what would have happened without the implementation of the promotion strategies. The basic model included terms to estimate the baseline level for each outcome (intercept) $\left(\beta_{0}\right)$, baseline trend 
(slope) $\left(\beta_{1}\right)$, changes in the level immediately after policy implementation $\left(\beta_{2}\right)$ and changes in the trend after the policy change $\left(\beta_{3}\right)$ (see the following model). ${ }^{25}{ }^{30}$ Our models also controlled for autocorrelation. ${ }^{31}$ To identify the most parsimonious models, we used backward elimination and excluded non-significant terms $(p>0.05)$.

$\mathrm{Y}_{\mathrm{t}}=\beta_{0}+\beta_{1} *$ time $_{\mathrm{t}}+\beta_{2} *$ intervention $_{\mathrm{t}}+\beta_{3} *$ time_after $_{-}$ intervention $\mathrm{t}_{\mathrm{t}} \mathrm{e}_{\mathrm{t}}^{25}$

To summarise the results as a single metric, we expressed policy intervention by using the relative difference between the actual value and the predicted value after the policy intervention, and we estimated the relative changes in the prescription rates and market shares (with $95 \% \mathrm{CIs})^{32}$ in outcomes 3 months following the interventions compared with projected rates. We calculated the relative change by using this formula: relative change $=($ actual value - predicted value $)$ in outcomes 3 months following the interventions/predicted value in outcomes 3 months following the interventions.

In addition, we selected patients who had used the targeted therapies during the study period, and based on the time of newly diagnosed NSCLC, time to prescription was used to represent the length of time required before use of the targeted therapies (representing the speed of drug accessibility). We also calculated the average of the difference between diagnosis date and the date of first use of the targeted therapies for each year over time. The relative changes of the average time to prescription (with $95 \% \mathrm{CIs})^{32}$ in outcomes 2 years following the interventions compared with projected rates were estimated. The relative changes were calculated using the following formula: relative change $=($ actual value - predicted value) in outcomes 2 years following the interventions/ predictedvalue in outcomes 2 years following the interventions. All analyses were carried out with SAS software, V.9.4 (SAS Institute, Cary, North Carolina, USA).

\section{Patient and public involvement}

Patients were not involved in this study.

\section{RESULTS}

Prescribing rate of targeted therapies by patient number

Claims data for a total of 92220 patients with NSCLC were collected. Table 1 presents the prescribing rate by patient number and the market share by cost of the targeted therapies over time. Overall, the number of patients who had used the targeted therapies (gefitinib and erlotinib) increased from 228 in 2004 to 8542 in 2013, which accounted for $5.48 \%$ of patients who had used antineoplastic agents in 2004 and $58.52 \%$ who had used them in 2013. Among these, the number of patients who had used gefitinib increased from 228 (5.48\% of patients who used antineoplastic agents) in 2004 to 5558 (38.08\%) in 2013; the number of patients who had used erlotinib increased from $499(8.44 \%)$ in 2007 to 2984 (20.44\%) in 2013.

\section{Market share of targeted therapies by cost}

During the 10-year study period, the estimated market share of targeted therapies by cost increased from

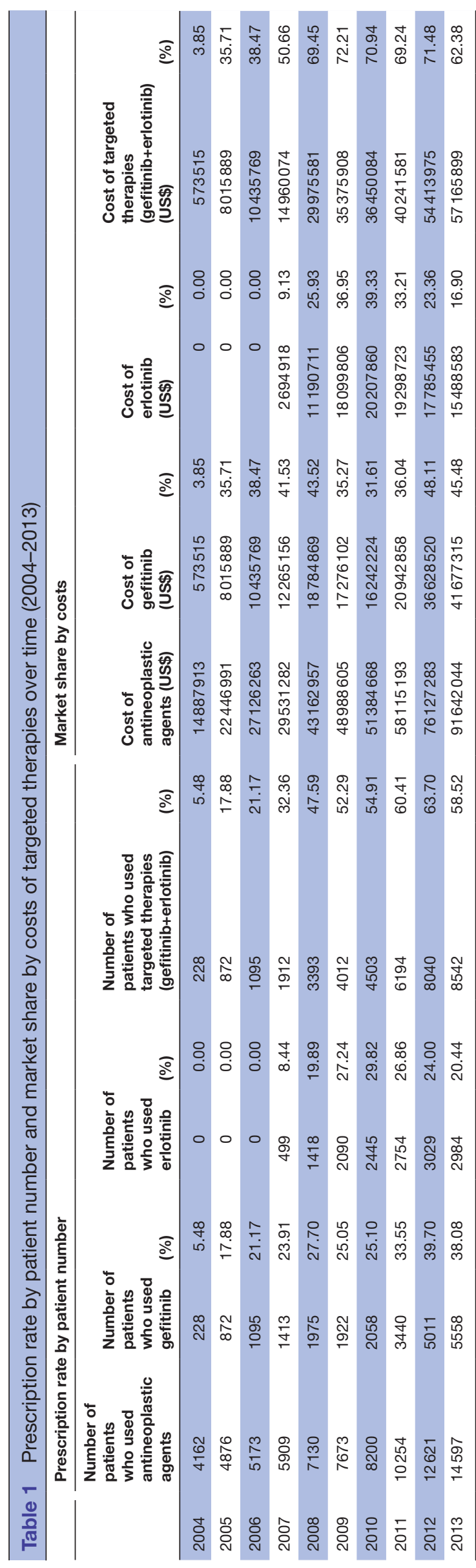


US\$573515 in 2004 to US\$57 165899 in 2013, which accounted for $3.85 \%$ in 2004 and $62.38 \%$ in 2013 of the cost of antineoplastic agents, respectively. Among these, the cost of gefitinib increased from US $\$ 573515$ (3.85\% of cost of antineoplastic agents) in 2004 to US\$41 677315 $(45.48 \%)$ in 2013; the cost of erlotinib increased from US\$2694 918 (9.13\%) in 2007 to US\$15 488583 (16.9\%) in 2013.

\section{Effects of multiple changes in reimbursement policies on the use of targeted therapies \\ Targeted therapies}

The prescribing rate of the targeted therapies remained steady after erlotinib was covered by NHI in June 2007 (table 2). There was a relative increase of $15.58 \%$ in the prescribing rate of the targeted therapies 3 months after gefitinib became available as a second-line treatment in November 2007, while there was a relative reduction of $10.98 \%$ after erlotinib became available as a second-line treatment in June 2008. After gefitinib became available as a first line-treatment in June 2011, it's usage rose relatively by $6.31 \%$. Figure 1 (A) shows the prescribing rate of the targeted therapies by patient number over time.

The market share of the targeted therapies by cost remained steady after erlotinib was covered by NHI in June 2007. Gefitinib became available as a second-line treatment in November 2007 and as a first line-treatment in June 2011. There was a relative decline of $4.33 \%$ in the market share of the targeted therapies by cost 3 months after erlotinib became available as a second-line treatment in June 2008.

\section{Gefitinib}

The prescribing rate of gefitinib decreased by $20.69 \%$ after erlotinib was covered by NHI in June 2007. It increased by $54.32 \%$, decreased by $13.27 \%$, and increased by $21.76 \%$ after gefitinib became available as a secondline treatment in November 2007; erlotinib became available as a second-line treatment in June 2008, and gefitinib became available as a first-line treatment in June 2011, respectively. Figure 1 (B) shows the prescribing rate of gefitinib by patient number over time.

There was a relative reduction of $6.59 \%$ in market share by cost for gefitinib after erlotinib was covered by NHI in June 2007. This did not change after gefitinib became available as a second-line treatment in November 2007, and erlotinib became a second-line treatment in June 2008. However, the market share by cost increased by $16.63 \%$ after gefitinib became available as a first-line treatment in June 2011.

\section{Erlotinib}

The prescribing rate of erlotinib declined relatively by $26.79 \%$ after gefitinib became available as a second-line treatment in November 2007. It increased by $22.62 \%$ and decreased by $10.3 \%$ after erlotinib became available as a second-line treatment in June 2008, and gefitinib became available as a first-line treatment in June 2011, respectively. Figure $1(\mathrm{C})$ shows the prescribing rate of erlotinib by patient number over time.

There was a relative reduction of $30.33 \%$ in market share by cost for erlotinib after gefitinib became available as a second-line treatment in November 2007. It increased by $21.66 \%$ and decreased by $9.3 \%$ after erlotinib became available as a second-line treatment in June 2008, and gefitinib became available as a first-line treatment in June 2011, respectively.

\section{Time to prescription of the targeted therapies}

The average time to prescription of the targeted therapies is shown in table 3 , and the estimated changes in time to prescription following changes in the reimbursement policies are presented in table 4 . The average time to prescription of the targeted therapies rapidly decreased from 802 days $(\mathrm{SD}=654.6)$ in 2004 to 43 days $(\mathrm{SD}=49.6)$ in 2013 (table 3) and reduced by $65.84 \%$ after erlotinib was covered by NHI, and gefitinib/erlotinib became available as second-line treatments in 2007 and 2008 and further decreased by $41.59 \%$ after gefitinib became available as a first-line treatment in 2011 (table 4). The average time to prescription of gefitinib decreased from 685 days ( $\mathrm{SD}=587.4$ ) in 2004 to 33 days $(\mathrm{SD}=33.7)$ in 2013 (table 3 ). There was a relative growth of $39.82 \%$ in time to prescription for gefitinib after erlotinib was covered by NHI, and gefitinib/erlotinib became available as second-line treatments, while there was a relative decline of $69.57 \%$ after gefitinib became a first-line treatment (table 4). The average time to prescription of erlotinib decreased from 1602 days $(\mathrm{SD}=520.7)$ in 2004 to 129 days $(\mathrm{SD}=70.8)$ in 2013 (table 3). It dropped substantially by $234.37 \%$ after erlotinib was covered by NHI, and gefitinib/erlotinib became available as second-line treatments, but it did not change after gefitinib became available as a first-line treatment (table 4).

\section{DISCUSSION}

Drug accessibility, especially the accessibility of expensive drugs that target cancer, has become the favourite topic of analysis of drug utilisation. ${ }^{33-35}$ Although some highly priced drugs have been approved for marketing, the reimbursement restriction from health insurance is an obstacle to drug accessibility. ${ }^{36}$ In this study, the data from NHIRD were used to examine the utilisation of targeted therapies for NSCLC during 2004-2013 (10 years). Using a strong quantitative research method (an interrupted time-series design), our findings revealed changes in the accessibility of the targeted therapies, including the prescribing rate, prescription speed and economic burden, following a series of reimbursement policy modifications.

It was found that four interventions had significant effects on the use of gefitinib and erlotinib. To understand the impacts of the drug reimbursement policy of 'removing reimbursement restrictions and broadening the eligible patient population', the prescribing rate and 


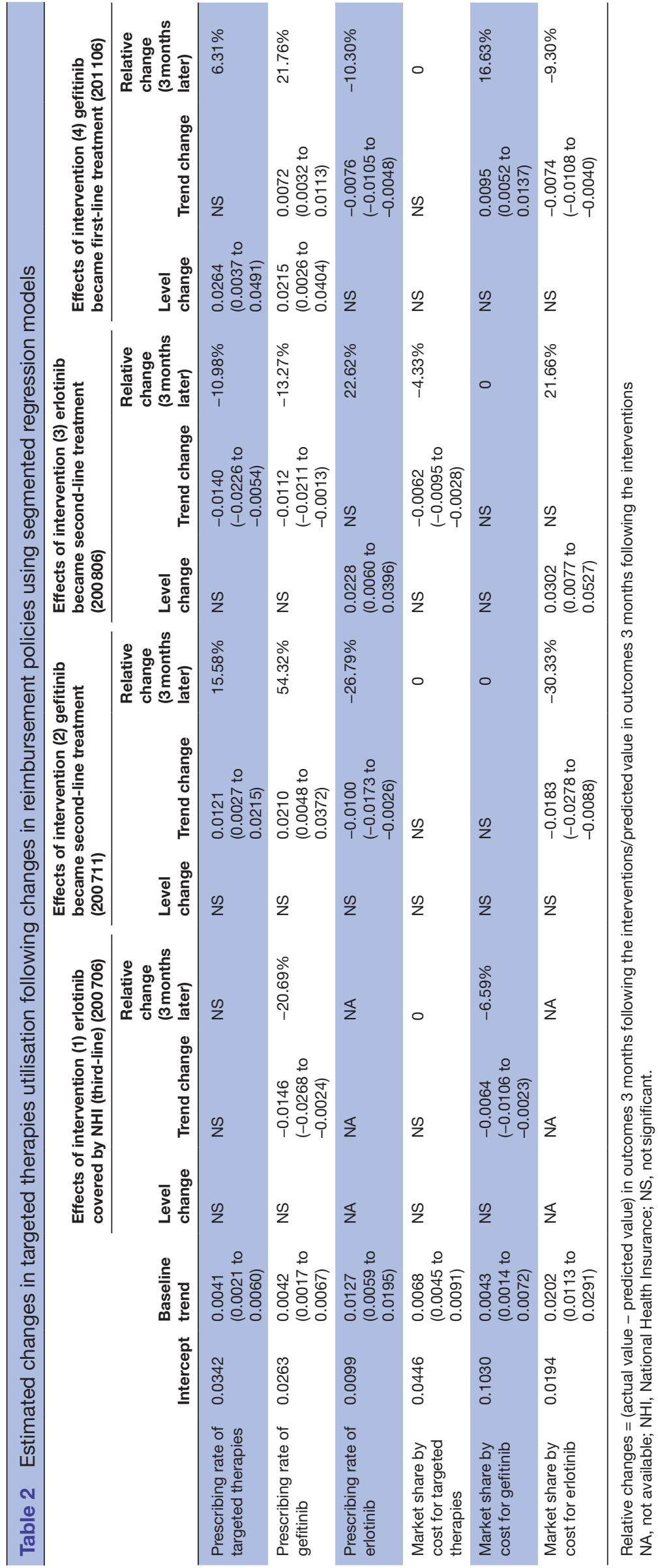


(A) Targeted therapies (gefitinib + erlotinib)

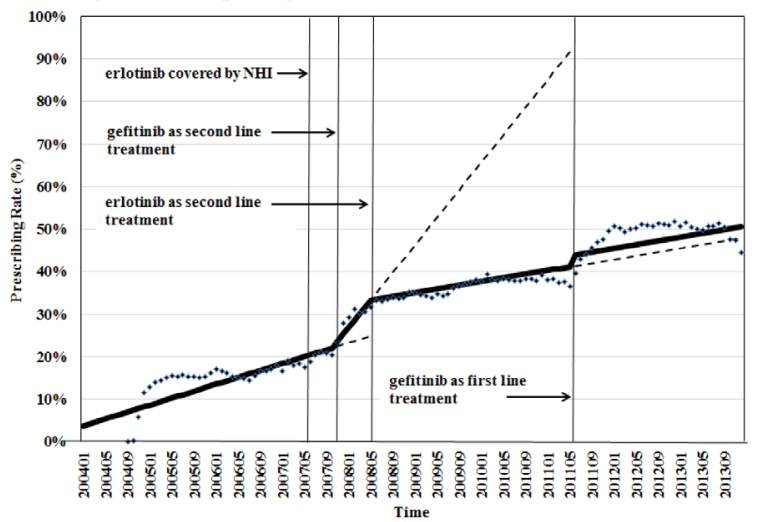

(B) Gefitinib

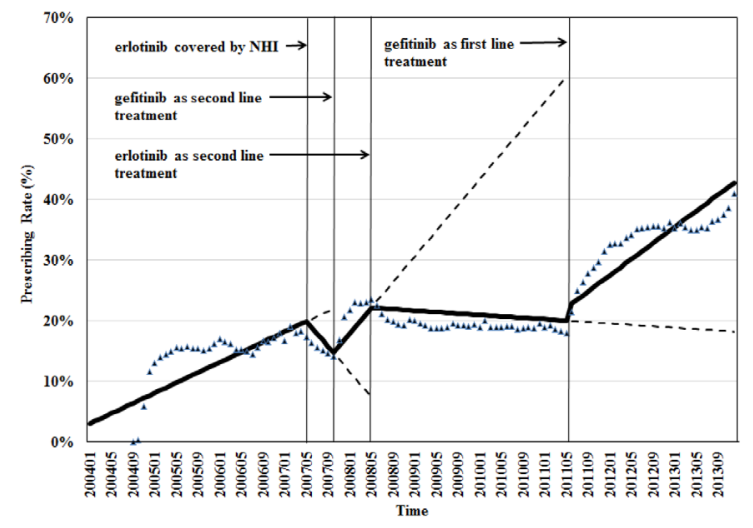

(C) Erlotinib

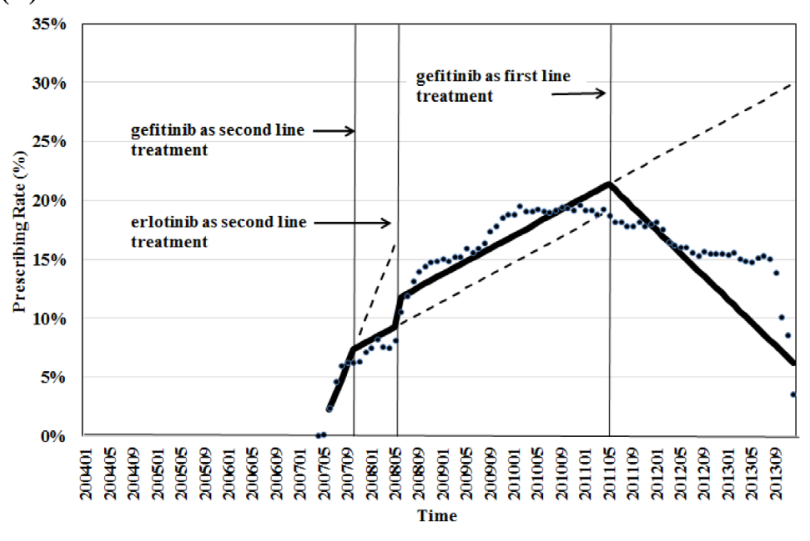

Figure 1 Prescribing rate by patient number of targeted therapies over time: (A) Targeted therapies (gefitinib +erlotinib). (B) Gefitinib. (C) Erlotinib. Prescription rate of targeted therapies by patient number=number of patients who used targeted therapies/number of patients who used antineoplastic agents. NHI, National Health Insurance .

prescription speed were used to represent the accessibility of drugs. The results made it possible to determine whether 'removing reimbursement restrictions and broadening the eligible patient population' actually allowed more patients to have access to targeted therapies.

In the case of gefitinib, the prescribing rate has steadily risen since it was first covered by NHI in 2004. Then, the coverage of erlotinib (as a third-line treatment) for NSCLC resulted in a drop in gefitinib by $20 \%$ (prescribing rate) and $6 \%$ (market share by expenditure). A few months later, availability of gefitinib as a second-line treatment resulted in the greatest changes in gefitinib use (a 54.32\% increase). When erlotinib became available as a secondline treatment, gefitinib's use reduced by $13 \%$. Then, gefitinib's prescribing rates and expenditures rose again (a $21 \%$ increase in prescribing rate and a $17 \%$ increase in expenditures) when gefitinib became available as firstline treatment.

In the case of erlotinib, three changes in reimbursement rules had significant effects on prescribing rates and market share by cost. Especially, after gefitinib became available as a second-line treatment, the prescribing rate and market share of cost decreased by $27 \%$ and $30 \%$, respectively. In addition, the previous rates of erlotinib reduced by $10 \%$ and $9 \%$, respectively, after gefitinib became available as a first-line treatment. On the other hand, when erlotinib became available as a second-line treatment, approximately $23 \%$ and $22 \%$ increases in prescribing rates and market share by cost were observed, respectively.

The overall use of oral targeted therapies (gefitinib and erlotinib) did not rise following the introduction of erlotinib in June 2007. However, their use significantly rose by $15 \%$ when gefitinib became available as a second-line treatment in November 2007, while it fell by $10 \%$ when erlotinib became available as a second-line treatment in June 2008. When gefitinib became available as a first-line treatment, the overall prescription rate of oral targeted therapies only increased by $6 \%$. On the other hand, the market share of cost of oral targeted therapies was only slightly diminished when erlotinib became available as a second-line treatment in June 2008, but it was not affected by other interventions. In general, these changes in the reimbursement rules were effective with regard to improving the accessibility of the targeted therapies.

As for the speed of accessibility of the targeted therapies related to NSCLC treatment, the average time to prescription for targeted therapies gradually reduced from 802 days in 2004 to 43 days in 2013. This means the changes in the reimbursement rules (removing reimbursement restriction and broadening the eligible patient population) markedly accelerated the accessibility of the targeted therapies.

Past research indicates that the accessibility of a drug is related to the health insurance coverage proportion. ${ }^{37} 38$ This study used the accessibility of the targeted therapy for NSCLC treatment; for example, it further proved that in health insurance, removing reimbursement restrictions can significantly increase the accessibility of drugs and the speed of accessibility of drugs. Although the accessibility of drugs has increased through changes in health insurance policies, healthcare resource allocation and health inequalities between various cancer types or diseases are issues that need to be subsequently followed up.

This study has several limitations. First, the study focused on the effects of removing reimbursement 
Table 3 Time to prescription of targeted therapies for non-small cell lung cancer treatment over time (2004-2013)

Time to prescription (days)

\begin{tabular}{|c|c|c|c|c|c|c|}
\hline & \multicolumn{6}{|c|}{ IIme to prescription (days) } \\
\hline & Mean & SD & Mean & SD & Mean & SD \\
\hline 2004 & 801.7 & 654.6 & 685.3 & 587.4 & 1602.0 & 520.7 \\
\hline 2005 & 683.4 & 546.2 & 570.0 & 497.4 & 1128.7 & 500.4 \\
\hline 2006 & 603.0 & 471.2 & 522.1 & 440.9 & 743.2 & 489.4 \\
\hline 2008 & 383.0 & 343.7 & 390.1 & 379.9 & 377.6 & 313.1 \\
\hline 2009 & 369.3 & 315.7 & 382.1 & 340.7 & 359.2 & 294.2 \\
\hline 2010 & 329.8 & 242.9 & 325.6 & 247.7 & 333.4 & 238.8 \\
\hline 2011 & 207.2 & 207.0 & 137.9 & 182.4 & 313.5 & 197.2 \\
\hline
\end{tabular}

restrictions and broadening the eligible patient population in relation to the accessibility of medicines. We used three indicators: prescribing rate, market share of cost and time to prescription, as measurements of accessibility of medicine. Due to the lack of clinical test data in the Taiwan NHIRD claims database, this study was not able to identify patients' eligibility to obtain the targeted therapies based on clinical testing (such as pathology or cytological results and EGFR gene mutation test results, etc). Second, in this study, data from the Taiwan NHIRD claims database were analysed; these data did not cover data for payments made by the patients themselves. Hence, there may be differences between the estimated prescription rate/costs and the actual value. However, this gap is not believed to be very significant since the proportion of payments made by patients themselves was very small. Third, considering the timing of drug launches, during the study period (2004-2013), only two first-generation targeted therapies (gefitinib and erlotinib) could be included, and newer medicines were out of the scope of this study. Finally, this study was aimed towards an examination of the effects of removing reimbursement restrictions and broadening the eligible patient population related to accessibility to the targeted therapies. In future there is a need for further studies on how such policies affect the clinical outcomes of treatments and the cost-effectiveness of the policies.

\section{CONCLUSION}

The present study examined how multiple, separate changes in reimbursement policies have changed drug utilisation and accessibility of the targeted therapies. Overall, removing reimbursement restrictions and broadening the eligible patient population for NSCLC-targeted therapies improved the accessibility of such medications. In detail, when a targeted therapy became available for either early or broad use, utilisation increased, but this

Table 4 Estimated changes in average time to prescription for non-small cell lung cancer targeted therapies following changes in reimbursement policies

\begin{tabular}{|c|c|c|c|c|c|}
\hline \multicolumn{3}{|c|}{$\begin{array}{l}\text { Impact of erlotinib covered by NHI and gefitinib/ } \\
\text { erlotinib as second-line treatments in } 2007 \text { and } \\
2008\end{array}$} & \multicolumn{3}{|c|}{ Impact of gefitinib as first-line treatment in 2011} \\
\hline Level change & Trend change & $\begin{array}{l}\text { Relative } \\
\text { change } \\
\text { (2 year later) }\end{array}$ & Level change & Trend change & $\begin{array}{l}\text { Relative } \\
\text { change } \\
\text { (2year later) }\end{array}$ \\
\hline NS & $\begin{array}{l}67.9176 \\
(41.1362 \text { to } \\
94.6990)\end{array}$ & $\begin{array}{l}-65.84 \% \\
(-68.30 \% \text { to } \\
-63.37 \%)\end{array}$ & NS & $\begin{array}{l}-45.3087 \\
(-72.0901 \text { to } \\
-18.5273)\end{array}$ & $\begin{array}{l}-41.59 \% \\
(-57.24 \% \text { to } \\
-25.93 \%)\end{array}$ \\
\hline NS & $\begin{array}{l}51.1611 \\
(23.5177 \text { to } \\
78.8045)\end{array}$ & $\begin{array}{l}39.82 \% \\
(9.87 \% \text { to } \\
69.77 \%)\end{array}$ & $\begin{array}{l}-182.0687 \\
(-245.2401 \text { to } \\
-118.8973)\end{array}$ & NS & $\begin{array}{l}-69.57 \% \\
(-81.08 \% \text { to } \\
-58.07 \%)\end{array}$ \\
\hline NS & $\begin{array}{l}316.5921 \\
(260.7650 \text { to } \\
372.4192)\end{array}$ & $\begin{array}{l}-234.37 \% \\
(-318.17 \% \text { to } \\
-150.57 \%)\end{array}$ & NS & NS & $0.00 \%$ \\
\hline
\end{tabular}

Relative changes $=$ (actual value - predicted value) in outcomes 2 years following the interventions/predicted value in outcomes 2 years following the interventions NA, not available; NHI, National Health Insurance; NS, not significant. 
may have, in turn, decreased the use of other similar classes of drugs. In addition, the targeted therapies were prescribed faster once their insurance reimbursement restrictions were lifted. The results of this study can be used as the empirical basis for clinical treatment, to help enhance the content of academic literature on this subject, and can serve as the empirical basis for future targeted therapy studies.

Contributors JCH and S-CY conceptualised and designed the study. C-FW collected data, performed analysis and drafted the manuscript. JCH and S-CY reviewed all data and revised the manuscript critically for intellectual content. All authors approved the final version for submission.

Funding JCH was supported by the Taiwan Ministry of Science and Technology grants (Grant ID: MOST 104-2320-B-006-005, MOST 106-2320-B-006-039).

Competing interests None declared.

Patient consent for publication Not required.

Provenance and peer review Not commissioned; externally peer reviewed.

Data sharing statement The authors have obtained nationwide, monthly claims data for NSCLC patients, from 2004 to 2013, from the Taiwan National Health Insurance Research Database (NHIRD).

Open access This is an open access article distributed in accordance with the Creative Commons Attribution Non Commercial (CC BY-NC 4.0) license, which permits others to distribute, remix, adapt, build upon this work non-commercially, and license their derivative works on different terms, provided the original work is properly cited, appropriate credit is given, any changes made indicated, and the use is non-commercial. See: http://creativecommons.org/licenses/by-nc/4.0/.

\section{REFERENCES}

1. Ferlay J, Shin HR, Bray F, et al. Estimates of worldwide burden of cancer in 2008: GLOBOCAN 2008. Int J Cancer 2010;127:2893-917.

2. American Cancer Society. Cancer facts \& figures. Atlanta: American Cancer Society, 20122012.

3. Cancer Registry Annual Report, 2011. Health promotion administration, ministry of health and welfare. Taiwan, 2014

4. Pfizer Oncology. Lung cancer fact sheet. 2012.

5. Reade CA, Ganti AK. EGFR targeted therapy in non-small cell lung cancer: potential role of cetuximab. Biologics 2009;3:215-24.

6. Alvarez M, Roman E, Santos ES, et al. New targets for non-small-cell lung cancer therapy. Expert Rev Anticancer Ther 2007;7:1423-37.

7. Ohe Y, Ohashi Y, Kubota K, et al. Randomized phase III study of cisplatin plus irinotecan versus carboplatin plus paclitaxel, cisplatin plus gemcitabine, and cisplatin plus vinorelbine for advanced nonsmall-cell lung cancer: Four-Arm Cooperative Study in Japan. Ann Oncol 2007;18:317-23.

8. Chen HL, Shen LJ, Wei CP, et al. Decision to adopt medical technology under the National Health Insurance System in Taiwan: case study of new molecular targeted drugs among non-small cell lung cancer patients. J Eval Clin Pract 2015;21:808-16.

9. Shepherd FA, Rodrigues Pereira J, Ciuleanu T, et al. Erlotinib in previously treated non-small-cell lung cancer. N Engl J Med 2005;353:123-32.

10. Cataldo VD, Gibbons DL, Pérez-Soler R, et al. Treatment of nonsmall-cell lung cancer with erlotinib or gefitinib. N Engl J Med 2011;364:947-55

11. National Comprehensive Cancer Network. Non-small cell lung cancer. 2013 http://www.nccn.org/index.asp (Accessed 19 Dec 2015)

12. Maemondo M, Inoue A, Kobayashi K, et al. Gefitinib or chemotherapy for non-small-cell lung cancer with mutated EGFR. $N$ Engl J Med 2010;362:2380-8.

13. Jiang $\mathrm{H}$. Overview of gefitinib in non-small cell lung cancer: an asian perspective. Jpn J Clin Oncol 2009;39:137-50.

14. Mok TS, Wu YL, Thongprasert S, et al. Gefitinib or carboplatinpaclitaxel in pulmonary adenocarcinoma. N Engl J Med 2009;361:947-57.

15. Sun JM, Lee KH, Kim SW, et al. Gefitinib versus pemetrexed as second-line treatment in patients with nonsmall cell lung cancer previously treated with platinum-based chemotherapy (KCSGLU08-01): an open-label, phase 3 trial. Cancer 2012;118:6234-42.

16. Mitsudomi T, Morita S, Yatabe Y, et al. Gefitinib versus cisplatin plus docetaxel in patients with non-small-cell lung cancer harbouring mutations of the epidermal growth factor receptor (WJTOG3405): an open label, randomised phase 3 trial. Lancet Oncol 2010;11:121-8.

17. Wu YL, Chu DT, Han B, et al. Phase III, randomized, open-label, first-line study in Asia of gefitinib versus carboplatin/paclitaxel in clinically selected patients with advanced non-small-cell lung cancer: evaluation of patients recruited from mainland China. Asia Pac J Clin Oncol 2012;8:232-43.

18. Kim ST, Uhm JE, Lee J, et al. Randomized phase II study of gefitinib versus erlotinib in patients with advanced non-small cell lung cancer who failed previous chemotherapy. Lung Cancer 2012;75:82-8.

19. Urata Y, Katakami N, Morita S, et al. Randomized Phase III study comparing gefitinib with erlotinib in patients with previously treated advanced lung adenocarcinoma: WJOG 5108L. J Clin Oncol 2016;34:3248-57.

20. Zhou C, Wu YL, Chen G, et al. Erlotinib versus chemotherapy as first-line treatment for patients with advanced EGFR mutationpositive non-small-cell lung cancer (OPTIMAL, CTONG-0802): a multicentre, open-label, randomised, phase 3 study. Lancet Oncol 2011;12:735-42.

21. Haspinger ER, Agustoni F, Torri V, et al. Is there evidence for different effects among EGFR-TKIs? Systematic review and meta-analysis of EGFR tyrosine kinase inhibitors (TKIs) versus chemotherapy as firstline treatment for patients harboring EGFR mutations. Crit Rev Oncol Hematol 2015;94:213-27.

22. Burotto M, Manasanch EE, Wilkerson J, et al. Gefitinib and erlotinib in metastatic non-small cell lung cancer: a meta-analysis of toxicity and efficacy of randomized clinical trials. Oncologist 2015;20:400-10.

23. Liu SZ, Romeis JC. Assessing the effect of Taiwan's outpatient prescription drug copayment policy in the elderly. Med Care 2003:41:1331-42.

24. Analytic Hierarchy Process. Theory and practice. $2009 \mathrm{ftp}: / /$ mail.im. tku.edu.tw/Prof_Shyur/AHP/AHP2009.pdf (Accessed 15 Dec 2017).

25. Wagner AK, Soumerai SB, Zhang F, et al. Segmented regression analysis of interrupted time series studies in medication use research. J Clin Pharm Ther 2002;27:299-309.

26. Cy L, Ross-Degnan D, Stephens P, et al. Changes in use of antidiabetic medications following price regulations in China (1999-2009). J Pharm Health Serv Res 2013:4:3-11.

27. Lu CY, Zhang F, Lakoma MD, et al. Changes in antidepressant use by young people and suicidal behavior after FDA warnings and media coverage: quasi-experimental study. BMJ 2014:348:g3596.

28. Hsu JC, Lu CY, Wagner AK, et al. Impacts of drug reimbursement reductions on utilization and expenditures of oral antidiabetic medications in Taiwan: an interrupted time series study. Health Policy 2014;116:196-205

29. Lu CY, Soumerai SB, Ross-Degnan D, et al. Unintended impacts of a medicaid prior authorization policy on access to medications for bipolar illness. Med Care 2010;48:4-9.

30. Serumaga B, Ross-Degnan D, Avery AJ, et al. Effect of pay for performance on the management and outcomes of hypertension in the United Kingdom: interrupted time series study. BM 2011;342:d108.

31. Shadish WC, Campbell TD. Experimental and quasi-experimental designs for generalized causal inference: Houghton Mifflin, 2002.

32. Zhang F, Wagner AK, Soumerai SB, et al. Methods for estimating confidence intervals in interrupted time series analyses of health interventions. J Clin Epidemiol 2009;62:143-8.

33. Lewin J, Siu LL. Cancer genomics: the challenge of drug accessibility. Curr Opin Oncol 2015;27:250-7.

34. Morgan S, Kennedy J. Prescription drug accessibility and affordability in the United States and abroad. Issue Brief 2010;89:1-12.

35. Davidoff AJ, Guy GP, Hu X, et al. Changes in health insurance coverage associated with the affordable care act among adults with and without a cancer history: population-based national estimates. Med Care 2018;56:220-7.

36. Saab S, Jimenez M, Fong $T$, et al. Accessibility to oral antiviral therapy for patients with chronic hepatitis $C$ in the United States. $J$ Clin Transl Hepatol 2016;4:76-82.

37. Kuhlthau KA, Nipp RD, Shui A, et al. Health insurance coverage, care accessibility and affordability for adult survivors of childhood cancer: a cross-sectional study of a nationally representative database. $J$ Cancer Surviv 2016;10:964-71.

38. Takayama A, Narukawa M. Comparison of new drug accessibility and price between japan and major european countries. Ther Innov Regul Sci 2017; 51:604-11. 